\title{
A imposição do caráter social da produção por meio da concorrência
}

André Guimarães Augusto Professor associado do Departamento de Economia da UFF

\section{Palavras-chave \\ concorrência, regulação turbulenta, equilíbrio.}

Classificação JEL B14, D40, P12.

\section{Key words}

competition, turbulent

regulation, equilibrium

JEL Classification B14, D40,

P12

\section{Resumo}

O objetivo deste trabalho é demonstrar que para Marx o caráter social da produção capitalista é imposto aos produtores privados por meio da concorrência. Uma consequência direta dessa forma de resolução do caráter social da produção é que a reprodução social tem caráter turbulento, que contrasta com a ideia de equilíbrio.

\section{Abstract \\ The aim of this paper is to show that for Marx, the social character of capitalist production is imposed upon private producers through com- petition. One direct consequence of this type of resolution of the social nature of production is that social reproduction has a turbulent character that contrasts with equilibrium.}




\section{1_Introdução}

A produção mercantil tem como pressuposto o seu caráter social. Para que haja produção de mercadorias, é necessária uma divisão do trabalho, em que as diferentes atividades são interdependentes, na qual cada uma trabalha para os outros. No entanto, esse caráter social não pode ser efetuado diretamente, uma vez que a outra condição para a existência da mercadoria é a propriedade privada e a autonomia dos produtores. Assim, o caráter social da produção, ou seja, a distribuição dos diversos trabalhos privados de acordo com as necessidades da sociedade precisa ser imposta aos produtores privados.

O objetivo deste trabalho é demonstrar que para Marx o caráter social da produçẫo capitalista é imposto aos produtores privados por meio da concorrência. Uma consequência direta dessa forma de resolução do caráter social da produção é que a reprodução social tem uma característica turbulenta, que contrasta com a ideia de equilíbrio.

$\mathrm{Na}$ primeira seção deste artigo, são mostrados os determinantes da concorrência entendida como rivalidade. $\mathrm{Na}$ segunda seção, apresentam-se os mecanismos pelos quais a concorrência intrarramos impóe o caráter social da produção, o mesmo sendo feito para a concorrência inter-ramos na seção seguinte. $\mathrm{Na}$ quarta seção, a ideia de uma regulação turbulenta da reprodução social é contrastada com a de equilíbrio. $\mathrm{O}$ artigo termina com algumas considerações finais

\section{2_A natureza da concorrência}

O fundamento da concorrência se encontra no caráter mercantil da sociedade burguesa. A relação mercantil é uma situação contraditória de produtores privados vinculados pela divisão social do trabalho, e a reprodução de sua condição de proprietários privados requer a validação de seus trabalhos como parte da divisão social do trabalho. A concorrência é, por um lado, uma relação de separação entre os produtores privados e, por outro, é o vínculo que os iguala na sua determinação de proprietários privados.

A validação do trabalho de produtores privados como parte da divisão social do trabalho é alcançada pela realização das mercadorias. Mas não há nenhuma garantia de que isso ocorra: cada produtor privado decide sem interferência direta de outros o que, como e quanto produzir e sem o conhecimento das 
necessidades sociais e da quantidade de trabalho que deve ser alocada na produção de cada mercadoria para satisfazêlas. A interação entre os produtores e o conhecimento a posteriori das necessidades sociais se dão por meio das coisas, da oferta de determinado tipo de mercadoria no mesmo mercado pelos seus diferentes proprietários.

$\mathrm{Na}$ ausência de interação direta entre os produtores e de consciência sobre as necessidades sociais, o isolamento dos proprietários privados leva esses a se apresentarem como rivais na disputa pela realização de sua mercadoria. A concorrência é um processo de disputa, de luta, análogo a uma guerra de todos contra todos; nesse aspecto, tem caráter contraditório, já que une os proprietários privados por meio de sua separação.

Assim, a concorrência se enraíza na propriedade privada e na consequente necessidade de realização da mercadoria, sem a precisão de se evocar a busca de lucros. Dessa forma, pode-se explicar a existência de concorrência entre os trabalhadores - proprietários privados da mercadoria força de trabalho, mas que não buscam o lucro - a que Marx se refere (Marx, 1987, Livro I, p. 633, 641, 738; Livro III, p. 198). Marx é explicito ao atribuir a concorrência en- tre os trabalhadores ao caráter mercantil de sua relação:

Esses operários, constrangidos a venderse diariamente, são mercadoria, artigo de comércio como qualquer outro; em consequência sujeitos a todas as vicissitudes da concorrência, a todas as flutuaçôes do mercado (Marx, 1989, p. 370).

A concorrência, portanto, é uma forma de sociabilidade estranhada: na disputa pela realização das mercadorias, cada um aparece como meio - por meio do dinheiro - ou obstáculo - pela venda da mesma espécie de mercadoria no mesmo mercado - para os outros.

O caráter especificamente capitalista da concorrência acrescenta novas determinaçóes ao conceito. Se a concorrência entre os capitalistas inclui a disputa pela realização das mercadorias, seu objeto fundamental é a distribuição da mais-valia (Marx, 1987, Livro III, p. 179180). A mais-valia é um produto da relação entre a classe capitalista e a classe trabalhadora; mas sua distribuição não se dá de forma igualitária entre os diversos capitais devido à diversidade de condiçóes de produção:

Os capitalistas dos diferentes ramos, ao venderem as mercadorias, recobram os valores de capital consumidos para produzi-las, mas, a mais-valia (ou lu- 
cro) que colhem não é a gerada no próprio ramo com a respectiva produção de mercadorias e sim a que cabe a cada parte alíquota do capital global, numa repartição uniforme da mais-valia (ou lucro) global produzida, em dado espaço de tempo, pelo capital global da sociedade em todos os ramos (Marx, 1987, Livro III, p. 180).

Assim, cada capital busca a obtenção de no mínimo o lucro médio e se possível mais lucros.

A disputa pela participação na mais-valia implica que a concorrência entre os capitais se estende por diversos campos e se reveste de diversas formas: a concorrência se estabelece entre capitais produtores de mercadorias no interior de um ramo de produção e entre diferentes ramos, entre as diversas formas funcionais do capital - produtor de mercadorias, produtor de juros, comercial - e entre os diversos capitais particulares em suas várias formas funcionais. A concorrência se determina aqui como forma generalizada de relação entre os diversos capitais.

A determinação da concorrência como separação de produtores privados permanece, mas ganha um novo aspecto quando considerado seu caráter capitalista: a separação entre os trabalhadores e os meios de vida. O fundamento da con- corrência capitalista é a propriedade dos meios de vida - de produçáo e subsistência - pela classe capitalista. Sem a propriedade dos meios de vida pelos capitalistas, seria impossível a transformação da força de trabalho em mercadoria e consequentemente a produção de maisvalia e a disputa por sua distribuição entre os capitais particulares. Em outras palavras, é o monopólio dos meios de vida pela classe capitalista que gera a concorrência entre os capitais pela repartição da mais-valia.

\section{A concorrência intrarramos}

A concorrência é o meio pelo qual se reproduz para cada proprietário privado sua associação como componentes da divisão do trabalho/proprietários monopolistas dos meios de vida, ou seja, o caráter social da produção se impóe para cada capital particular por meio da concorrência. Nesta seção, são apresentados os processos por meio dos quais a concorrência intrarramos impóe o caráter social da produção aos capitais particulares.

O ponto de partida para compreender como a concorrência impóe o caráter social da produção para cada produtor é o reconhecimento das diferenças nos métodos produtivos e consequente- 
mente nos diversos graus de produtividade dos capitais particulares. Tal diferença decorre das diversidades técnicas na produção de distintas mercadorias e especialmente da propriedade privada; como cada produtor decide sem a interferência direta de outros como produzir, a propriedade privada gera a diferença entre métodos produtivos. Assim, há uma diversidade de condiçóes de produção resultante das decisões isoladas dos produtores de mercadorias. Isso, como será visto adiante, é reproduzido pela concorrência.

Com métodos produtivos díspares, os diversos capitais particulares despendem quantidades de trabalho desiguais para produzir a mesma mercadoria, originando, assim, diferenças no valor individual das mercadorias. Mas, se a oferta das mercadorias é capaz de satisfazer a procura - isto é, se não há diferença entre o valor e o preço de mercado -, as mercadorias são vendidas pelo seu valor de mercado, que corresponde "ao valor médio das mercadorias produzidas em um ramo" (Marx, 1987, Livro III, p. 202).

A desigualdade entre os valores individuais e o valor de mercado acarreta uma redistribuição da mais-valia gerada em um ramo de produção. Os capitais que produzem mercadorias com valor individual acima do valor de mercado terão parcela da mais-valia realizada pelos trabalhadores que empregam apropriada pelos capitais que fabricam mercadorias com valor individual abaixo do valor de mercado, que dessa forma realizam uma mais-valia extraordinária ou superlucro. Já os capitais que produzem mercadorias com valor individual igual ao valor de mercado realizam somente a mais-valia gerada pelos trabalhadores que empregam (Marx, 1987, Livro III, p. 202).

A disputa pela participação na mais-valia produzida em um ramo, ocasionada pela diferença entre valor individual e valor de mercado, leva os diversos capitais a buscarem a igualação entre o valor individual das mercadorias que produzem e o valor de mercado, de forma a se apropriarem da mais-valia por eles produzidas. Mais ainda, na busca de mais-valia extraordinária, os diversos capitais procuram reduzir seu custo de produção, diminuindo (reduzindo), assim, o valor individual das mercadorias por eles feitas em relação ao valor de mercado. $\mathrm{O}$ meio para isso é a introdução de novos métodos mais produtivos que diminuam o valor individual da mercadoria (Marx, 1987, Livro I, cap. 10).

Assim, a concorrência - a disputa pela participação na mais-valia produzi- 
da em um ramo - impóe para cada capital particular a busca do tempo de trabalho socialmente necessário, o dispêndio de trabalho na produção de mercadorias de acordo com as necessidades sociais (Marx, 1987, Livro III, p. 217); em outras palavras, a concorrência impóe para cada capital particular o caráter social da produção de mercadorias.

O resultado dessa busca, no entanto, não é uma situação de equilíbrio em que a diferença entre os capitais seja eliminada e na qual o valor individual de todas as mercadorias se iguale necessariamente ao valor de mercado. A busca por mais-valia extraordinária leva os diversos capitais a implementarem métodos mais produtivos de forma constante; os capitais particulares não se contentam em alcançar o nível médio de produtividade. Em resumo, a concorrência é um processo contínuo e incessante que, embora leve os capitais particulares a buscarem reduzir tendencialmente suas desigualdades, acaba por reproduzi-las.

A imposição do caráter social da produção capitalista pelo processo incessante da concorrência leva também a outros resultados e se reveste de outra forma. A introdução de métodos mais produtivos por alguns capitais em um ramo de produçáo leva a um aumento da oferta de mercadorias nesse ramo; sem um aumento correspondente da procura solvente, os capitais que introduzem o novo método têm, por um lado, a necessidade de oferecer suas mercadorias a preços mais baixos que o valor de mercado para conseguir realizar uma quantidade maior de mercadorias. Por outro lado, os capitais que empregam métodos mais produtivos têm a possibilidade de ofertar suas mercadorias a preços menores que o valor de mercado, uma vez que, com métodos mais produtivos, é possível fazê-lo e ainda assim obter uma mais-valia extraordinária, desde que o preço de mercado esteja acima do valor individual dessas mercadorias (Marx, 1987, Livro I, p. 367-368).

A concorrência gera, assim, a divergência entre preço e valor de mercado, e com isso seu aspecto mercantil se evidencia: os capitais concorrem pela realização de suas mercadorias. Essa disputa desencadeia uma ação em massa, com os diversos produtores seguindo a baixa de preços iniciada pelos capitais mais produtivos, com vista a realizar a mercadoria, mesmo que apenas pelo preço de custo. Esse movimento de ação em massa também se observa no caso contrário, em que a procura é maior que a oferta e na qual os capitais mais produtivos tendem a seguir alta de preços para aumentar sua mais-valia extraordinária: 
"O individuo age aí como parte de uma força social, como átomo de massa, e é sob essa forma que a concorrência faz valer o caráter social da produção e do consumo" (Marx, 1987, Livro III, p. 218-219).

Dessa forma, a disputa pela realização das mercadorias e pela participação na mais-valia entre os capitais particulares desencadeia uma ação em massa no mercado que evidencia o caráter social da produção, a interdependência oculta dos capitais na produção de mercadorias e na apropriação de mais-valia.

$\mathrm{Na}$ situação em que o preço de mercado se encontra abaixo do valor de mercado, alguns capitais não conseguem nem recuperar seu preço de custo, e dessa forma podem ficar impossibilitados de se reproduzirem como produtores privados, isto é, desaparecem ou são absorvidos pelos capitais mais produtivos, dando origem ao processo de centralização do capital (Marx, 1987, Livro I, p. 727).

A referida divergência entre preço e valor de mercado desencadeia a busca de métodos mais produtivos por parte dos capitais que produzem com valor individual acima do valor de mercado. Quando os métodos mais produtivos se difundem, o valor médio das mercadorias, e dessa forma o valor de mercado, cai. Mas o movimento inces- sante da concorrência assinalado anteriormente não garante que o novo valor de mercado vai convergir para o preço de mercado; as oscilações do preço de mercado e sua divergência com o valor de mercado permanecem.

\section{A concorrência inter-ramos}

A descrição do processo de imposição do caráter social da produção por meio da concorrência se restringiu até aqui a um ramo de produçấo. A disputa pela maisvalia, no entanto, estende-se por toda a estrutura social da produção, não se restringindo aos diferentes ramos da divisão social do trabalho. A concorrência inter-ramos é uma forma necessária e pelo menos táo importante quanto aos outros tipos de concorrência. O capital é riqueza em abstrato, cuja finalidade é a obtenção de valor excedente, pouco lhe importando o caráter do valor de uso que produz. A transferência de capital inter-ramos está de acordo com a natureza do capital em geral, e a maior ou menor possibilidade dessa transferência depende das condiçóes da concorrência.

As diferenças entre os capitais se referem também às condições médias de produção dos diversos ramos da divisão social do trabalho, e, da mesma forma que as diferenças no interior de 
um ramo, geram diversidade na apropriação da mais-valia e na taxa de lucro (Marx, 1987, Livro III, cap. 9).

Os ramos de produção com produtividade média acima da média social têm composição orgânica maior que a média e por isso produzem lucros proporcionais ao capital empregado menores do que a média, isto é, possuem taxas de lucro menores que a taxa média ou geral de lucro. O inverso é válido para os ramos com produtividade média abaixo da média social - isto é, em que o valor de mercado é maior que o valor médio de mercado de todos os ramos - que possuem taxa de lucro acima da média.

Essas divergências na taxa de lucro ou no lucro como proporção do capital geram uma disputa geral pela mais-valia global. À medida que, em determinados ramos de produção, a taxa de lucro se apresenta abaixo da média, os capitais desses ramos se deslocarão para os outros ramos, principalmente sob a forma de novos capitais, gerando, assim, uma tendência à igualação da taxa de lucro no nível correspondente à taxa média de lucro. Há um fluxo ininterrupto de capital entre os ramos de produção, que dá origem à tendência de equalização da taxa de lucro, de formação tendencial de uma taxa média de lucro.

\section{1_o "problema da transformação"}

A venda das mercadorias de acordo com seu valor de mercado é incompatível com a taxa uniforme de lucro. As mercadorias devem ser vendidas a um preço tal que permita aos diversos capitais do mesmo montante obterem a mesma taxa de lucro. Em outras palavras, o preço da mercadoria não corresponde mais ao seu valor de mercado, mas sim à soma do preço de custo - isto é, do custo dos meios de produção e de força de trabalho consumidos na produção - e o lucro médio relativo ao capital em questão. Os preços que proporcionam o lucro médio na venda da mercadoria são os preços de produção.

Essa nova determinação dos preços das mercadorias suscitou intenso debate que ficou conhecido na literatura como o "problema da transformação dos valores em preço". Sem querer esgotar, no espaço deste trabalho, os pontos principais dessa discussão, procurarei esclarecer alguns aspectos centrais para a argumentação deste artigo.

É preciso lembrar, de início, que o debate envolve duas questóes intimamente relacionadas, mas nem sempre tratadas conjuntamente: de um lado, a possibilidade de determinação quantitativa dos preços de produção a partir do valor e, do outro, a possibilidade (e 
a necessidade) de se derivar conceitualmente os preços de produção a partir do valor.

Primeiramente, vou me deter na natureza da relação entre valores e preços. É preciso lembrar que a diferença entre valores e preços é conceitual antes de ser quantitativa. Não há uma identidade primitiva entre valores e preços. Os preços são apenas a expressão monetária da quantidade de trabalho contida em uma mercadoria, isto é, do valor. Dessa forma, impóe-se, desde o começo, uma diferença conceitual, entre um conteúdo essencial (valor) e sua forma aparente e necessária (preço).

Valor e preços são mensurados por unidades diferentes - horas de trabalho, no caso do valor, e unidades monetárias, no caso do preço - e distintos quantitativamente, antes mesmo de se considerar a taxa média de lucro. Desta forma, a possibilidade ou não de uma determinação quantitativa estrita entre valores e preços não pode servir de parâmetro para conclusóes acerca da relação entre essas duas categorias - o que não invalida a discussão do problema formal, tornando-o apenas um problema subordinado ao problema conceitual. A relação entre valor e preço deve ser analisada, primeiramente, do ponto de vista qualitativo, conceitual.
A relação aqui proposta entre essas duas categorias é de precedência teórica dos valores sobre os preços. Deve-se lembrar primeiramente de que os preços, enquanto expressão monetária do valor, dependem da formulação do próprio conceito de dinheiro, sem o que fica incompreensível sua natureza. Mas a natureza do dinheiro só pode ser explicada em sua gênese a partir do valor. É da necessidade da mercadoria expressar sua contradição como coisa útil (valor de uso) e coisa social (valor) que surge o dinheiro e, consequentemente, a expressão monetária do conteúdo social da mercadoria, seu valor, sob a forma de preço. Como afirma Marx:

O valor da mercadoria continua a ter importância fundamental, porque só se pode estudar racionalmente o dinheiro a partir dessa base, e o preço em sua conceituação geral, é antes de mais nada valor na forma de dinheiro (Marx, 1987, Livro III, p. 218).

A precedência teórica do valor pode ser observada também quando se trata dos preços de produção. Estes últimos são uma decorrência da equalização tendencial da taxa de lucro, e sua determinação conceitual (e quantitativa) fica dependente da determinação anterior da natureza e da origem do lucro. O lucro só pede ser entendido como valor 
excedente, tempo de trabalho excedente. Senão vejamos.

Como bem demonstra Marx, o lucro não pode ter sua origem na circulação. $\mathrm{Na}$ circulação, em seu funcionamento normal, ocorre apenas uma mudança de forma. O pressuposto da circulação é que se troquem equivalentes, o que impede o surgimento de um valor excedente na circulação. Por outro lado, a origem do lucro também não pode ser encontrada na troca de não equivalentes. Se o que se busca explicar é o lucro por algum privilégio dos compradores ou dos vendedores de burlar a troca de equivalentes, esquece-se de que, na circulação, os produtores se alternam na posição de compradores e vendedores, e o que era lucro em um momento é compensado por uma perda no momento seguinte.

Finalmente, deve-se lembrar da impossibilidade de se derivar o lucro do processo de produção em geral, uma vez que nesse só ocorre a transformação de coisas úteis e, portanto, não há a criação de valor extra, além do adiantado no início do processo. A equação meios de produção $=$ lucros, além do erro de identificar o capital, determinação histórica dos meios de produção, com os meios de produção em geral independentemente de sua determinação histórica, é uma relação que iguala desiguais, coisas físicas e valor.

Dessa forma, a origem e a natureza do lucro só podem ser entendidas a partir da utilização da mercadoria força de trabalho, além do tempo necessário para a sua reprodução. A natureza do lucro consiste, então, em ser valor excedente e só assim pode ser entendido. Afirma-se, portanto, a necessidade da análise do valor antes da análise dos preços de produção, ou seja, sua precedência técnica.

A precedência dos valores também é necessária para explicar os movimentos dos preços de produção, que são regulados pelos movimentos dos valores. Se examinarmos os seus componentes, ou seja, taxa média de lucro e preço de custo, veremos que toda variação nos preços de produção pode ser encarada como resultante de variaçóes no valor. A taxa média de lucro só se alterará mediante modificaçôes na taxa de mais-valia - o que significa dizer no valor da força de trabalho e, portanto, no valor das mercadorias que entram na sua reposição - ou na composição média do capital, com alteraçóes na produtividade do trabalho e, por isso, no valor de outras mercadorias.

Cabe assinalar que nem sempre a relação entre variaçóes no valor e na ta- 
xa média de lucro é tão direta; outros fatores afetam a taxa de lucro: uma alteração na jornada de trabalho pode atingir a taxa de mais-valia e, por conseguinte, a taxa média de lucro. Da mesma forma, o tempo de rotaçáo ou a economia no uso dos meios de produçáo pode afetar a taxa média de lucro; nesses casos, porém, há uma ligação ainda que indireta com alterações do valor das mercadorias, pois se trata de alteraçóes que resultam, de uma forma ou de outra, do aumento geral de produtividade (Marx, 1987, Livro III, Cap. iv, p. 94). O preço de custo, por sua vez, somente se alterará modificando-se a produtividade do trabalho - e dessa forma o valor - seja na produção da mercadoria em questáo, seja na produção das mercadorias que são utilizadas em sua produção (Marx, 1987, Livro III, p. 232; Rubin, 1980, p. 253-254 e 267).

Existem dois procedimentos para determinação quantitativa dos preços de produção. $\mathrm{O}$ primeiro procedimento é o do sistema simultâneo (Bortkiewicz, 1952). Nesse sistema, são determinados simultaneamente os preços de produção dos insumos e dos produtos e a taxa de lucro. Esse procedimento é compatível com o equilíbrio, e não com a regulação turbulenta. O sistema simultâneo supóe que a taxa de lucro seja efetivamente igual e que o seu processo de equali- zação se dê de forma instantânea em um período. Ao considerar que os preços dos insumos sejam o mesmo do produto, o sistema admite preços constantes ao longo do tempo, não podendo representar o processo de mudança nos preços e eliminando qualquer fonte de variação no processo de formação da taxa média de lucro (Freeman, 1995). Assim, embora a determinação dos preços de produção seja o resultado do movimento dos capitais, o sistema simultâneo considera que esse movimento não existe em uma situação de equilíbrio.

O outro procedimento de determinação quantitativa dos preços de produção com base nos valores é o do sistema temporal único (Kliman; McGlone, 1999). Nesse sistema, os preços de produção são obtidos a partir dos valores de forma sequencial e interdependente. Nessa abordagem, o preço de custo é tomado como um dado, estabelecido no período anterior, e com base nele e na taxa média de lucro se determinam os preços de produção dos produtos. Os preços de produção são aplicados nos insumos no período seguinte, e os novos preços de produção têm de ser calculados para o novo preço dos insumos, e assim por diante.

Essa determinação sequencial dos preços de produção, além de reproduzir 
o procedimento de Marx em O capital, reflete o processo real de equalização da taxa de lucro como um processo de ajuste contínuo em que os preços de custo já foram pagos e os capitais reagem à concorrência, ajustando os preços correntes dos produtos (Shaikh, 1977, p. 131). Nessa forma de entender o processo de determinação dos preços de produção, a concorrência é apreendida como um processo contínuo, e não como um mecanismo que permite o alcance do equilíbrio estático, como no sistema simultâneo (Freeman, 1995).

\section{2_Concorrência inter-ramos e caráter social da produção}

Deve se revisar de forma breve o mecanismo da concorrência inter-ramos. Os capitais migram entre os ramos de produção, principalmente sob a forma de novos capitais, em busca da maior taxa de lucro; a migração de capitais tende a igualar as taxas de lucros dos diferentes ramos de produção, gerando, assim, os preços de produção. Assim os capitais, por meio de novos investimentos de lucros retidos, tendem a sair dos ramos em que os valores de mercado estão abaixo dos preços de produção; o contrário ocorre nos ramos em que os valores de mercado estão acima dos preços de produção. Esse movimento tende a estabelecer preços de produção e taxas de lucro iguais nos diferentes ramos da produção (Marx, 1987, Livro III, p. 221).

A redistribuição da mais-valia entre os diferentes capitais particulares ocorre, então, na sociedade como um todo. Nas condiçôes em que os preços de produção estão estabelecidos, a mais-valia gerada nos ramos em que o valor de mercado está acima dos preços de produção é apropriada pelos capitais dos ramos em que o valor de mercado está abaixo dos preços de produção. Isso porque, nestes últimos, a mercadoria é vendida por preços de produção acima dos valores de mercado, consistindo essa diferença na mais-valia apropriada pelos capitais do referido ramo.

O movimento migratório dos capitais não elimina as flutuaçóes dos preços de mercado; pelo contrário, a transferência de capitais entre diferentes ramos é um elemento a mais na determinação dessas flutuações. Quando a oferta é maior que a procura - devido, por exemplo, a introdução de métodos mais produtivos em um ramo de produção -, os preços de mercados tendem a cair e com isso diminuir os lucros médios de um ramo de produção. Isso leva à saída de capitais do ramo, tendendo, assim, a conduzir os preços de mercado em direção aos preços de produção; o inverso ocorre quando da elevação dos preços 
de mercados em um ramo. Dessa forma, como o "movimento dos capitais é determinado primordialmente pela conjuntura dos preços de mercado"(Marx, 1987, Livro III, p. 235), o movimento incessante da concorrência não garante que o preço de mercado vai convergir para o preço de produção; as oscilações do preço de mercado e sua divergência com o preço de produção permanecem.

A concorrência pela redistribuição da mais-valia global por meio da migração de capitais, principalmente sob a forma de novos capitais, é também um meio pelo qual se impóe o caráter social da produção. Primeiramente, a redistribuição da mais-valia pela produção tendencial da taxa média de lucro e dos preços de produção impóe para cada capital particular o caráter de classe da relação entre capital e trabalho. Em segundo lugar, a distribuição do trabalho de acordo com as necessidades sociais também é imposta para cada produtor privado por esse meio; quando diminui o tempo de trabalho socialmente necessário o valor de mercado - em um ramo de produção, o lucro médio do ramo diminui, levando os capitais a migrarem desse ramo e, dessa forma, ajustando tendencialmente a quantidade de trabalho empregada nesse ramo à socialmente necessária (Rubin, 1980, p. 247-252).

\section{5_Regulação turbulenta e as ilusões do equilíbrio}

A imposição do caráter social da produção por meio da concorrência traz como consequência o caráter turbulento da reprodução social. Dada a configuração das relaçôes de produção mercantis, as decisões e ações dos diversos capitais precisam ser reguladas socialmente para que haja a reprodução da divisão do trabalho. Essa regulação tem caráter turbulento isto é, sujeito a mudanças contínuas e imprevistas - uma vez que não é realizada de forma consciente pelos agentes.

Tomemos o caráter turbulento do processo de migração dos capitais, mecanismo fundamental da concorrência inter-ramos. A redistribuição da mais-valia entre os ramos de produçáo pelo movimento migratório dos capitais não elimina a distribuição no interior de um ramo. Em outras palavras, essa distribuição se refere às condições médias de produção nos diferentes ramos, subsistindo ainda as diferenças de condições de produção no interior de um ramo. A busca por novos métodos mais produtivos - e a consequente variação dos preços de mercado - permanece, portanto, como um efeito da concorrência.

Se a busca por novos métodos mais produtivos permanece, as condiçóes médias de produção em cada ramo 
estão sujeitas a mudança pela concorrência. Isso significa que a taxa uniforme de lucro se estabelece apenas de forma tendencial, sendo a resultante necessária somente como tendência, do fluxo de capitais inter-ramos. Marx assinala o caráter ideal desse centro de flutuaçôes eternas:

Entre os ramos que mais se aproximam da média, ocorre a mesma tendência à uniformização, no sentido de chegar ao centro, de natureza ideal, pois inexistente na realidade, isto é, a tendência a normalizar-se segundo o próprio centro (Marx. 1987, Livro III, p. 197 - ênfase adicionada).

Diversos são os fatores que impedem a efetivação plena da lei de equalização da taxa de lucro: as diferenças nos tempos de rotaçáo entre os diversos ramos, as barreiras à mobilidade do capital e as diferenças de produtividade dentro de cada ramo de produção impedem que se estabeleça a taxa uniforme de lucro como taxa efetiva, observável de forma imediata. De acordo com Marx,

\section{a própria taxa geral de lucro aparece apenas como limite minimo do lucro, e não como figura empírica, logo visí- vel da taxa efetiva de lucro (Marx, 1987, vol. III, p. 424 - ênfase adicionada).}

Seu estatuto é apenas tendencial, e o fluxo de capitais é um fluxo ininterrupto; a taxa geral de lucro é apenas a média reguladora de um processo turbulento. De acordo com Marx,

\section{[...] em toda produção capitalista a lei geral só se impóe como a tendência do- minante, de maneira aproximativa $e$ muito baralhada, transparecendo em média móvel de flutuações eternas (Marx, 1987, Livro III, p. 183 - ênfase adicionada).}

A tendência à uniformização da taxa de lucro não nos indica ser impossível a existência em determinado momento do tempo de diferenciais de taxa de lucro entre os diversos ramos. Segundo Marx,

as taxas de lucro nos diferentes ramos de produção são mais ou menos incertas; mas, ao aparecerem, o que se revela não é a uniformidade e sim a diversidade delas (Marx, 1987, Livro III, p. 424).

Nesse aspecto, a lei determina apenas a impossibilidade da existência de uma estrutura de taxas de lucro permanente, estática, entre os diversos ramos. A mobilidade do capital dinheiro, a dinâmica de cada ramo, no que se refere a sua organização, e a busca incessante da taxa média de lucro por parte dos capitais levam a que mais cedo ou mais tarde haja uma modificação na estrutura de taxas de lucro inter-ramos. Conforme afirma Shaikh, 
since old methods are constantly eliminated and new ones constantly added, this intra-industrial constellation of profit rates is perpetually recreated by the dinamics of accumulation (Shaikh, 1982, p. 77).

Uma segunda consequência da imposição do caráter social da produção pela concorrência se refere às crenças ilusórias geradas pelo processo de concorrência e que são formuladas pelas teorias econômicas dominantes mediante a análise do equilíbrio. O elemento principal a ser enfatizado nesse aspecto é que o caráter social da produção pressuposto e imposto para os proprietários privados e capitais particulares por meio da concorrência parece ser gerado por essa. Em outras palavras, o caráter social da produção revela-se na consciência dos agentes da concorrência como um resultado de suas açôes individuais. Essa é a principal inversão efetuada pela concorrência: o que é pressuposto parece resultado, o que é social manifesta-se como soma da ação de indivíduos isolados.

Tal inversão gerada pela concorrência apresenta-se nas formulaçóes do equilíbrio da teoria dominante. Nessas formulações, o equilíbrio é o resultado da concorrência, entendida como ação de indivíduos isolados no mercado. Cada agente da concorrência é tomado co- mo um átomo, definido por suas preferências, pelas dotaçóes e pela tecnologia. $\mathrm{O}$ resultado da interação entre os agentes isolados é um estado que garante a reprodução da ordem social de forma a que todos estejam na melhor situação possível.

Não é demais ressaltar todos os contrastes entre o processo turbulento da concorrência real e a crença no equilíbrio como resultado da concorrência. $\mathrm{O}$ resultado da concorrência não é um estado de equilíbrio, mas um processo de regulaçáo turbulenta no qual se impóe o caráter social da produção (Shaikh, 1990, p. 79). Pelo contrário, em um estado de equilíbrio - em que as taxas de lucros seriam equalizadas, a demanda seria igual à oferta em todos os mercados e consequentemente os preços de mercado, os preços de produção e os valores de mercado seriam iguais, e não haveria progresso tecnológico -, a concorrência deixaria de existir. Segundo Marx,

[...] a coincidência entre a procura e a oferta equivale à eliminaçấo do desvio entre preços de mercado e os preços médios reguladores, isto é, à eliminaçấo da concorrência [...] (Marx, 1987, Livro III, p. 988).

Embora as condiçóes definidoras do equilíbrio da teoria econômica dominante não sejam exatamente as mesmas, 
é possível observar a ausência da concorrência no estado de equilíbrio. $\mathrm{O}$ equilíbrio supóe que todos os agentes que atuam no mercado estejam em igualdade de condiçóes, mas a concorrência na realidade efetua um duplo movimento: se por um lado ela tende a eliminar as desigualdades entre os produtores privados, o faz recriando-as.

O mesmo caráter ilusório se encontra no caráter harmônico - descrito de forma pretensamente neutra como ótimo - do estado de equilíbrio supostamente resultante da concorrência. Tal ideia de ordem harmônica como resultado da ação isolada de indivíduos no mercado já se encontra formulada na mão invisível de Adam Smith. Ao contrário do caráter harmônico e do estado de calma contidos na noção de equilíbrio, a concorrência efetua uma reprodução social que se dá de forma turbulenta e conflituosa, em uma permanente guerra de todos contra todos, onde cada um, ao buscar a realização de seu "interesse", não garante o sucesso na sua reprodução como proprietário privado.

\section{6_Considerações finais}

Este artigo apresentou o argumento de que o caráter social da produção capitalista de mercadorias é imposto pela con- corrência. Seja no interior de um ramo, seja entre ramos, é o mecanismo de preços regulados pelos valores e a busca do lucro que impóem o caráter social da produção como coerção externa para cada um dos capitais individuais.

Imposto por meio da concorrência, a regulação da reprodução social só pode ser um processo conflituoso e turbulento fora do controle dos agentes, ao contrário do que propóe a ilusão do equilíbrio.

Este último aspecto nos leva a uma conclusão com respeito à concorrência como meio de imposição do caráter social da produção. $\mathrm{O}$ caráter conflituoso e turbulento da reprodução social é resultante de uma sociabilidade estranhada. A concorrência impóe a reprodução social como coerção impessoal: aqui se observa outra determinação do caráter de sociabilidade estranhada da concorrência; além de cada um ser apenas meio/obstáculo para os outros, a determinação social da produção se incute de forma coercitiva e impessoal. Cada produtor privado para se reproduzir enquanto tal se submete aos determinantes da reprodução social; mas o faz sem sabê-lo. A sociedade aparece para os agentes que a reproduzem por meio de sua ação como força estranha, como concorrência. 


\section{Referências bibliográficas}

BORTKIEWICZ, L. VON.

Value and price in the Marxian system. International Economic Papers, vol. 2, 1952.

FREEMAN, A. Marx without equilibrium. Capital \& Class, n. 56, Summer, 1995.

KLIMAN, A. J.; MCGLONE, T. A temporal single-system interpretation of Marx's Value Theory. Review of Political Economy, vol. 11, no 1, Jan. 1999.

MARX, K. O capital. Crítica da economia política. 3 vol. Sâo Paulo, DIFEL, 1987.

MARX, K. Burgueses e proletários. In: Fernandes, F. (Org). Marx Engels. História. Coleção grandes cientistas sociais. São Paulo: Ática, 1989.

RUBIN, I. I. A Teoria

Marxista do Valor. São

Paulo: Brasiliense, 1980.

SHAIKH, A. Marx's

Theory of Value and the transformation problem. In: SCHWARTZ, J. (Ed). The subtle anatomy of capitalism. Goodyear Publishing, 1977.

SHAIKH, A. Neo-Ricardian Economics: A wealth of algebra, a poverty of theory.
Review of Radical Political

Economics, vol. 14, n. 2, 1982.

SHAIKH, A. Valor, acumulación y crisis. Ensayos de Economia Política. Bogotá, Tercer Mundo Editores, 1990.

\section{E-mail de contato do autor}

andre@economia.uff.br

Artigo recebido em julho de 2008;

aprovado em março de 2010. 
